\title{
The Mitigation Design of Failure Conditions Level System with System Functional Hazard Assessment (SFHA) on Unmanned Aircraft MALE Class
}

\author{
Intan Novhela \\ Industrial Engineering Department \\ Telkom University \\ Bandung- 40257, Indonesia \\ intannovhelaa@student.telkomuniversity.ac.id
}

\author{
Sri Martini \\ Industrial Engineering Department \\ Telkom University \\ Bandung- 40257, Indonesia \\ srimartini@telkomuniversity.ac.id
}

DOI: $10.31364 / S C I R J / v 8 . i 12.2020 . P 1220828$

http://dx.doi.org/10.31364/SCIRJ/v8.i12.2020.P1220828

\begin{abstract}
Hazard in technological development can occur anywhere, anytime, and caused by various factors. Every technology product has the possibility to failed or error in its operation. This failure can endanger the product itself, its users or the environment around it.

The purpose of this research is to design mitigation for failure conditions at the system level in order to minimize and avoid the impact of failure conditions on an unmanned aircraft named PTTA MALE .The method used is descriptive qualitative method including architecture observation, discussion and interviews with experts. Research was also conducted using quantitative methods based on international standard documents (ARP 4761 \& STANAG 4671) to improve the analysis of failure conditions.

Mitigation design with a System Functional Hazard Assessment (SFHA) is carried out for each system level failure condition. Failure conditions are generally categorized into detected, undetected, announced and unannounced failures. When a failure condition occurs, the pilot can take action according to the best mitigation that has been designed, for example by turning off the automatic power control, or continuing the operation in manual mode. The results of this research can serve as a guide for pilots in operating PTTA MALE.
\end{abstract}

\section{Keywords: Technology, Hazards, Failure Conditions, Mitigation, SFHA}

\section{INTRODUCTION}

The system safety analysis is a very primary thing in developing a technology, including aircraft technology which is based on the scheme and architecture that has been designed [1]. Things that are analyzed are related to the system that regulates and operates an airplane, starting from what systems are on the aircraft, what is the function of each system and what are the approximate failure conditions that can occur in the system. This Analysis is at the system level and is known as System Functional Hazard Assessment (SFHA) [1].

ARP 4761 stands for Aerospace Recommended Practice 4761 is "Guidelines and Methods for Conducting the Safety Assessment Process on Civil Airborne Systems and Equipment". This guide provides guidelines for aircraft technology developers in terms of safety, starting from the requirements, verification and validation processes [2]. 
This research was conducted on a medium class unmanned aircraft known as PTTA MALE. PTTA MALE basically has 3 functions in its operation to surveillance, reconnaissance and combat. However, in carrying out these operations, there is a definite chance that failure may occur. before an impact occurs that can endanger and detrimental damage, this can be anticipated by analyzing and designing a mitigation of the failure condition.

The purpose of this study is to analyze failure conditions and design a mitigation of these failure conditions. the output is in the form of guidelines for pilots controlling PTTA MALE, so that when failure conditions occur, pilots can take the best action to minimize or avoid the dangers caused by the failure of this system level.

The research was conducted, starting with the rivew literature, conducting interviews with experts and studying the architecture of the system designed [3], after which a safety analysis was carried out [1].

The diagram above is a process flow in carrying out an aircraft safefty analysis as a whole, but for the system level analysis process, the process starts with the 3rd sequence, namely SFHA and so on PSSA (PSSA process is carried out for preliminary system level analysis / fault tree analysis) [1].

The purpose of this reserch is to find out :

1. Analyzing failure conditions that may occur in the operation of PTTA MALE

2. Analyze the effects that will occur on the PTTA MALE when a failure condition occurs

3. Mitigating failure conditions at PTTA MALE by knowing the recognition given by the aircraft

4. Mitigate and minimize failure conditions by analyzing what actions the pilot / ground crew should take when a failure occurs

5. Identify the types of failure conditions and their probabilities

If the system level analysis has been carried out, then this research can be useful for various parties, from the side of the technology developer, this analysis can become a requirement in conducting product certification, and can be used as a basis for making system improvements if there is a system that is at very dangerous risk. From the perspective of the pilot as the controller, the results of this study can be used as a guide in mitigating failure conditions, from the community's point of view, this research can be useful because accidents that may occur and can be dangerous, can be overcome and minimized.

\section{LITERATURE REVIEW}

\section{- Risk Management \& Hazard Analysis}

Risk is the variation in things that may occur and be experienced in a situation [4]. Risk is usually a threat that is received by the related parties, but not infrequently the risk can also be a benefit [5].

In general, the risk can be divided into 3 types [5] that is

1.Pure risk and speculative risk which is a risk that occurs naturally without any external factors causing it.

2. Risks to objects and people, this failure can endanger humans, objects or the environment around them.

3. Fundamental risk and particular risk

Hazard analysis is something that is done to identify, determine the risks and hazards that are likely to occur in a product / system in order to know their elimination and how to control those hazards.

\section{- Aircraft Safety Assessment Process (ARP 4761)}

ARP 4761 is a manual and method of implementing the safety assessment process on civilian airborne systems and equipment. This document describes the method and becomes a guideline in carrying out an aircraft safety analysis, this document can only be used for aircraft with industry standard and quality [1].

The sequence for conducting this analysis starts with the Aircraft Function Hazard Assessment (AFHA) and then continues with the Preliminary Aircraft Safety Assessment (PASA) after which it enters the SFHA (system function hazard assessment) and PSSA (Preliminary system safety assessment) stages [1]. 


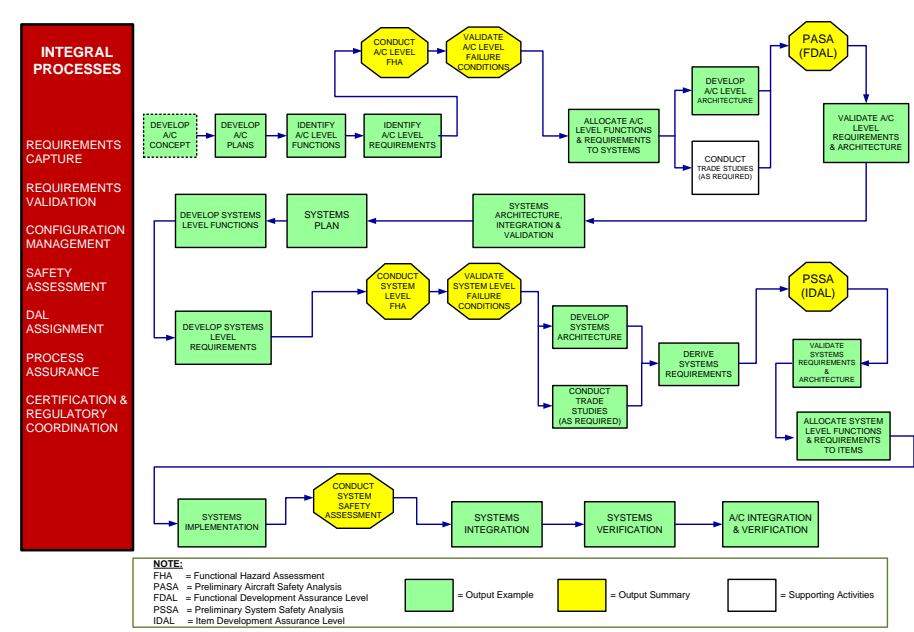

Figure 1. Integral Process

This cycle shows that, after the system design and architecture are completed, the next stage is to carry out safety planning for the system and architecture itself. This is done integrally, where when a security analysis is carried out and the system / architecture has a level of security that is less or can even cause danger, it can also be analyzed whether changes should be made to the system or simply by analyzing the mitigation that can be done to minimize and avoid possible danger.

\section{- System Functional Hazard Assessment (SFHA)}

The System Function Hazard Assessment examines how a component's operation or risk affects the system, SFHA determines how system operation and hazards can affect the safety of the system and its subsystems. The SFHA should begin when the system design matures, at the initial design review or facility design review milestone, and must be updated until the design is complete.

A person who performs and documents the SFHA to identify hazards and assess risks to the total system design, including software, and in particular the subsystem interfaces is called a safety analyst. This analysis should include an overview of subsystem relationships for:

1. Compliance with specified safety criteria

2. Independent, dependent and concurrent hazardous events including failure of safety devices and common causes that could create a hazard

3. Decrease the security of a subsystem or total system from the normal operation of other subsystems

4. Design changes affecting the subsystem
5. Effects of human error

6. The potential contribution of other software, events, errors, and events (such as bad timing) to system security

7. Determines whether the safety design criteria in the software specification have been met

\section{SAFETY ACTIVITY - DIAGRAM PROCESS PTTA MALE}

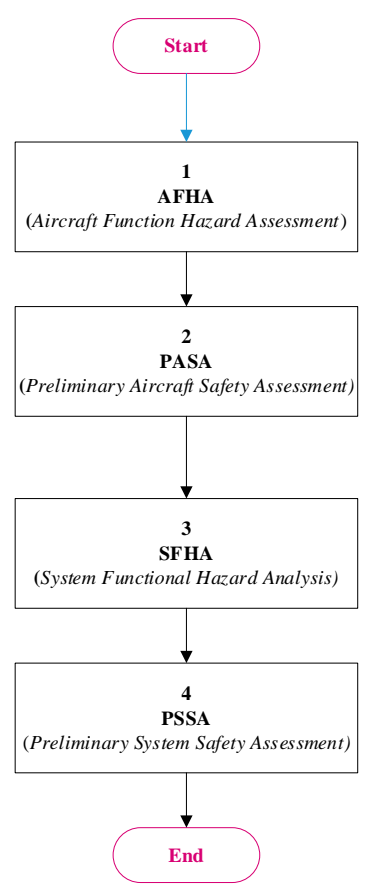

Figure 2. Safety Diagram Process

The diagram above is a process flow in carrying out an aircraft safefty analysis as a whole, but for the system level analysis process, the process starts with the 3rd sequence, namely SFHA and so on PSSA (PSSA process is carried out for preliminary system level analysis / fault tree analysis) [1].

The process of making and analyzing SFHA:

1. Identification of all functions related to the system level (internal functions and functions exchanged)

2. Identification of the failure conditions associated with this function, taking into account single and multiple failures in normal and degraded environments

3. Determination of the effect of failure conditions

4. Classification of failure conditions based on their impact on the aircraft, flight crew \& passengers

5. Assignment of requirements to failure conditions to be considered at a lower level

6. Identification of the supporting material required to justify the classification of the effect of the failure conditions

7. Identification of the method used to verify compliance with the failure condition requirements 
The next SFHA process is to determine the probability based on STANAG 4671, which is the standard or reference used to determine the severity of a failure condition on aircraft that have complex systems. Where the probability of a failure condition is shown in the table below :

Table 1. Classification and Probability of Hazard

\begin{tabular}{|c|c|}
\hline Classification & Probability \\
\hline Catastrophic & $10^{-7} / \mathrm{h}$ \\
\hline Hazardous & $10^{-6} / \mathrm{h}$ \\
\hline Major & $10^{-5} / \mathrm{h}$ \\
\hline Minor & $10^{-4} / \mathrm{h}$ \\
\hline No Safety Effect & $10^{-3} / \mathrm{h}$ \\
\hline
\end{tabular}

The military airworthiness standard refers to the safety assessment requirements using STANAG 4671 which is a specific standard that can be used for unmanned aircraft [6]. Because drones and airplanes with crew differ in severity, and the probability of such errors occurring is also different. To determine the classification of a failure condition, it can be described in the flow below:

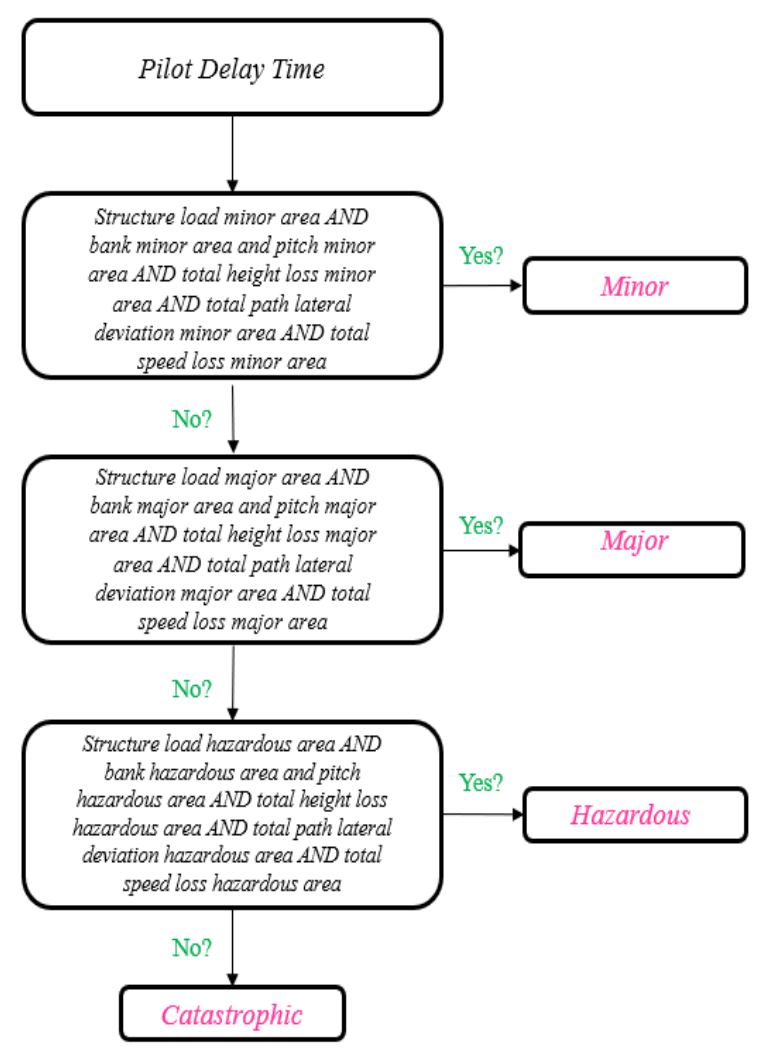

\section{Figure 3. Failure Classification}

\section{METHODOLOGY}

This research was conducted with a structured system to produce useful output for various parties. The method used is descriptive qualitative method including architectural observations and systems that have been designed, discussions with the developer and interviews with experts who are experts in the field of aircraft systems. Research was also conducted using quantitative methods in the form of grouping failure conditions based on international standard documents (ARP $4761 \&$ STANAG 4671) to improve the quality of the failure condition analysis.

The process of conducting the research begins with analyzing the failure conditions for each function system, after which an analysis of the impact that will occur due to the detected failure conditions is carried out. The next step is to design mitigation for these conditions, namely in the form of recognition mitigation that can be given and actions that can be taken to minimize and avoid these failure conditions. After knowing whether the action taken can minimize and overcome the failure condition or not, the failure condition is classified and given a probability of the possibility of the condition occurring.

\section{DISCUSSION}

Analysis of failure conditions is done by making a table of failure conditions, the phase of flight, the impact on the aircraft and the pilot, the recognition given, the actions that can be taken, the classification of failure conditions and their probability. as in the following table:

Table 2. SFHA Output

\begin{tabular}{|c|c|}
\hline Case Number & $x x-y y-z z z z$ \\
\hline Functional Hazard & Case 1 \\
\hline Flight Phase & Phase A \\
\hline 1. Effects on UAV/System/Ground Crew & 1. \\
2. Ground Crew Recognition & 2. \\
3. Ground Crew Action & 3. \\
\hline Criticallity & $A$ \\
\hline Probability & $B$ \\
\hline
\end{tabular}

The following is a detail flight phase from PTTA MALE:

Table 3. Detail Flight Phase

\begin{tabular}{|c|c|}
\hline Flight Phase & Descriptions \\
\hline START & Engine start \& Warming Up \\
\hline TAX & Taxi-out \\
\hline TO 1 & Takeoff Segment 1(Accelerate to V1) \\
\hline
\end{tabular}

vwW.scirj.org

(C) 2020, Scientific Research Journal

http://dx.doi.org/10.31364/SCIRJ/v8.i12.2020.P1220828

This publication is licensed under Creative Commons Attribution CC BY. 


\begin{tabular}{|c|c|}
\hline Flight Phase & Descriptions \\
\hline TO 2 & $\begin{array}{c}\text { Takeoff Segment 1(Accelerate from V1 to } \\
\text { VLOF) }\end{array}$ \\
\hline TO 3 & $\begin{array}{c}\text { Takeoff Segment } \text { (Accelerate from VLOF to } \\
\text { Altitude) }\end{array}$ \\
\hline TO 4 & $\begin{array}{c}\text { Takeoff Segment 3(Climb to Second Segment } \\
\text { Takeoff Segment 4(Climb from Second } \\
\text { Segment Altitude to Final Takeoff Altitude) }\end{array}$ \\
\hline TO 5 & Climb to Cruise-out Altitude \\
\hline CLB & Cruise-out to Surveillance Zone \\
\hline CRS & Descend to Surveillance Zone \\
\hline DSC & Cruise at Surveillance Zone \\
\hline CRS & Climb to Cruise-out Altitude \\
\hline CLB & Cruise-back to Base \\
\hline CRS & Descend to Holding Altitude \\
\hline DSC & Cruise at Holding Altitude \\
\hline CRS & Descend to Final Approach \\
\hline DSC & Final Approach \\
\hline APR & Landing Segment 1(50 ft to touch down) \\
\hline LND 1 & Landing Segment 2(deceleration from touch \\
\hline LND 2 & \\
\hline
\end{tabular}

PTTA MALE has 10 main function systems. Where each of these systems has their respective functions and duties in the operation of the aircraft. The 10 functions are as follows:

\section{Autoflight System (ATA 22)}

Autoflight System or in the world of aviation better known as ATA 22 is an automatic pilot system in a mechanical, electrical and hydraulic that regulates and guides the aircraft without human intervention. This system is designed to facilitate the work of ground pilots while doing their job. Because, if all systems are controlled manually, the probability of the pilot failure rate in controlling the aircraft will increase. However, it is possible that this automatic pilot system can also fail in operation.

This system has 4 system functions, along with an explanation and analysis of the failure conditions :

a. Provide automatic path control in flight operation (22-01)

b. Provide flight director in flight operation (22-02)

c. Provide automatic power control in flight operation (22-03)

d. Provide guidance control (22-04)

Based on the results of the analysis of system level failure conditions on the ATA 22 (Autoflight System) it is known that there are 51 types of failure conditions. 24 failure conditions were categorized as cathastrophic, 13 failure conditions were categorized as hazardous, 13 failure conditions were categorized as major and 1 failure condition was categorized as minor. The recognition required in this system is the presence of aural and visual data displayed on the monitor screen, so that the pilot knows that the UAV is experiencing a failure / damage to the ATA 22 system. Meanwhile, mitigation that can be done by pilots if detected and a failure condition occurs is by controlling the UAV. Manually. This could result in an increase in pilot workload, but the UAV will continue to operate and carry out its mission.

Table 4. Failure Condition-ATA 22

\begin{tabular}{|c|c|c|c|c|c|c|}
\hline \multirow{2}{*}{$\begin{array}{c}\text { System } \\
\text { Function }\end{array}$} & \multicolumn{4}{|c|}{ Failure Condition Classification } & \multirow{2}{*}{$\begin{array}{c}\text { Total } \\
\text { Case }\end{array}$} \\
\cline { 2 - 6 } & NSE & MIN & MAJ & HAZ & CAT & \\
\hline $22-01$ & 0 & 0 & 4 & 5 & 10 & 19 \\
\hline $22-02$ & 0 & 1 & 1 & 0 & 0 & 2 \\
\hline $22-03$ & 0 & 0 & 4 & 5 & 9 & 18 \\
\hline $22-04$ & 0 & 0 & 4 & 3 & 5 & 12 \\
\hline
\end{tabular}

The following is an example of a failure condition that has been analyzed at the ATA 22 system level :

Case Number : :22-01-001

Hazard : Unannunciated total loss of automatic path control during engagement

Flight Phase : CLB, CRS, DES

Effect : UAV cannot capture and hold commanded altitude, course, speed and execute contingency plan automatically, increasing ground crew workload

Recognition : Pilot recognize through difference between autopilot command and UAV flight parameter data and navigation data

Action $\quad$ : Ground crew shutting down automatic path control and execute contingency plan manually (UAV flight manual)

Criticallity : HAZ

Probability $: 10^{-5}$

2. Communication System Safety (ATA 23)

Communication System Safety or in the world of aviation better known as ATA 23 is a system that mediates communication from the pilot to the UAV. This system provides the function of transmitting and receiving data between pilots and the UAV. Data that is transmitted and received can visualize voice commands or control commands for the aircraft. All communication between the pilot and the UAV is regulated by the ATA 23 system, there are many possible failure conditions that can occur in this system, either due to internal factors or external factors that hinder the smooth running of this system. This system has 4 system functions, along with an explanation and analysis of the failure conditions : 
a. Provide UCS and UAV data transmission and reception for flight operation (23-01)

b. Provide UCS and UAV voice transmission and reception (2302)

c. Provide UCS data transmission and reception for payload operation (23-03)

d. Provide UAV data transmission and reception for payload operation (23-04)

Based on the results of the analysis of system level failure conditions on ATA 23 (Communication System Safety), it is known that there are 32 types of failure conditions. 7 failure conditions were categorized as cathastrophic, 16 failure conditions were categorized as hazardous, 4 failure conditions were categorized as major and 5 failure conditions were categorized as minor. The recognition required in this system is the presence of aural and visual data displayed on the monitor screen and recognizing failure conditions through the difference between automatic throttle commands and UAV flight parameter data so that the pilot knows that the UAV has failed / damaged the ATA 23 system. can be done by the pilot if detected and a failure condition occurs, namely by controlling the UAV manually. This could result in an increase in pilot workload, but the UAV will continue to operate and carry out its mission.

Table 5. Failure Condition - ATA 23

\begin{tabular}{|c|c|c|c|c|c|c|}
\hline \multirow{2}{*}{$\begin{array}{c}\text { System } \\
\text { Function }\end{array}$} & \multicolumn{4}{|c|}{ Failure Condition Classification } & \multirow{2}{*}{$\begin{array}{c}\text { Total } \\
\text { Case }\end{array}$} \\
\cline { 2 - 6 } & NSE & MIN & MAJ & HAZ & CAT & \\
\hline $23-01$ & 0 & 0 & 0 & 11 & 7 & 18 \\
\hline $23-02$ & 0 & 2 & 4 & 0 & 0 & 6 \\
\hline $23-03$ & 0 & 1 & 0 & 5 & 0 & 6 \\
\hline $23-04$ & 0 & 2 & 0 & 0 & 0 & 2 \\
\hline
\end{tabular}

The following is an example of a failure condition that has been analyzed at the ATA 23 system level :

$\begin{array}{ll}\text { Case Number } & : \text { 23-01-001 } \\ \text { Hazard } & \text { : Annunciated-detected erroneous data } \\ & \text { transmission from UCS to UAV } \\ \text { Flight Phase } & : \text { ALL } \\ \text { Effect } & : \text { Degraded performance of datalink } \\ \text { Recognition } & : \text { Ground crew recognize from aural and } \\ & \text { visual annunciation and aircraft response } \\ \text { Action } & : \text { Let UAV in contingency plan mode } \\ \text { Criticallity } & : \text { HAZ } \\ \text { Probability } & : 10^{-5}\end{array}$

3. Electrical System (ATA 24)

Electrical System or in the world of aviation better known as ATA 24 is a system that regulates all matters regarding electrical power that helps a UAV to operate. This function provides power generation and distribution of $\mathrm{AC}$ and $\mathrm{DC}$ power. Physically, this system is in a machine called electrical power. This system has 4 system functions, along with an explanation and analysis of the failure conditions :

a. Provide DC Electrical Power Generation (24-01)

b. Provide AC Electrical Power Generation (24-02)

c. Provide DC Electrical Power Distribution (24-03)

d. Provide AC Electrical Power Distribution (24-04)

Based on the results of the analysis of system-level failure conditions at ATA 24 (Electrical System), it is known that there are 23 types of failure conditions. 10 failure conditions are categorized as cathastrophic, 3 failure conditions are categorized as hazardous and 10 failure conditions are categorized as minor. The recognition required in this function system is a warning notification in the form of a warning alarm so that the pilot knows that the UAV is experiencing failure / damage to the ATA 24 system. Meanwhile, the mitigation that the pilot can do if a failure is detected and a failure condition occurs is to carry out emergency contingency plans. This could result in an increase in pilot workload, but the UAV will continue to operate and carry out its mission.

Table 6. Failure Condition-ATA 24

\begin{tabular}{|c|c|c|c|c|c|c|}
\hline \multirow{2}{*}{$\begin{array}{c}\text { System } \\
\text { Function }\end{array}$} & \multicolumn{4}{|c|}{ Failure Condition Classification } & \multirow{2}{*}{$\begin{array}{c}\text { Total } \\
\text { Case }\end{array}$} \\
\cline { 2 - 6 } & NSE & MIN & MAJ & HAZ & CAT & C \\
\hline $24-01$ & 0 & 4 & 0 & 2 & 3 & 9 \\
\hline $24-02$ & 0 & 4 & 0 & 1 & 6 & 11 \\
\hline $24-03$ & 0 & 1 & 0 & 0 & 1 & 2 \\
\hline $24-04$ & 0 & 1 & 0 & 0 & 0 & 1 \\
\hline
\end{tabular}

The following is an example of a failure condition that has been analyzed at the ATA 24 system level :

Case Number : 24-01-001

Hazard : Loss of main AC-DC converter under TBD

Flight Phase : ALL

Effect : Temporary loss of DC power from generator

Recognition : TRU loss indication active

Action : Release emergency contingency plan

Criticallity : HAZ

Probability $\quad: 10^{-5}$

4. Flight Control System (ATA 27)

Flight Control System or in the world of aviation better known as ATA 27 is used to control the effect of force on an airplane, direction of flight and attitude of an airplane. The main control system (Primary Control System) consists of: 1) Aileron (controls the rolling motion on the longitudinal axis), 2)

WWW.scirj.org

(C) 2020, Scientific Research Journal

http://dx.doi.org/10.31364/SCIRJ/v8.i12.2020.P1220828

This publication is licensed under Creative Commons Attribution CC BY. 
Elevator (controls the bobbing motion of the aircraft on the lateral axis), 3) Rudder (controls the aircraft movement on the vertical axis). These three are the main control systems and are used to control the aircraft so that it is safe and well controlled during flight. This system has 4 system functions, along with an explanation and analysis of the failure conditions :

a. Provide Roll Control Capability (27-01)

b. Provide Pitch Control Capability (27-02)

c. Provide Yaw Control Capability (27-03)

d. Provide High Lift Augmentation Capability (27-04)

This function system is a system that is the most risky compared to other systems. There are many possible failure conditions that occur in this system because the control surface that is included in the system is very complex and many. Based on the results of the analysis of system level failure conditions on ATA 27 (Flight Control System), it is known that there are 133 types of failure conditions. 52 failure conditions were categorized as cathastrophic, 38 failure conditions were categorized as hazardous and 43 failure conditions were categorized as major. The recognition required in this function system is very diverse, namely the presence of aural and visual data displayed on the monitor screen, notification in the form of a warning alarm so that the pilot knows that the UAV is experiencing a failure / damage to the ATA 27 system. and a failure condition occurs, namely by controlling using a control surface that can still be controlled, so that the aircraft can still be operated even though using manual methods. This could result in an increase in pilot workload, but the UAV will continue to operate and carry out its mission.

Table 7. Failure Condition-ATA 27

\begin{tabular}{|c|c|c|c|c|c|c|}
\hline \multirow{2}{*}{$\begin{array}{c}\text { System } \\
\text { Function }\end{array}$} & \multicolumn{4}{|c|}{ Failure Condition Classification } & \multirow{2}{*}{$\begin{array}{c}\text { Total } \\
\text { Case }\end{array}$} \\
\cline { 2 - 6 } & NSE & MIN & MAJ & HAZ & CAT & \\
\hline $27-01$ & 0 & 0 & 11 & 3 & 10 & 24 \\
\hline $27-02$ & 0 & 0 & 16 & 14 & 18 & 48 \\
\hline $27-03$ & 0 & 0 & 16 & 14 & 18 & 48 \\
\hline $27-04$ & 0 & 0 & 0 & 7 & 6 & 13 \\
\hline
\end{tabular}

The following is an example of a failure condition that has been analyzed at the ATA 27 system level :

\begin{tabular}{|c|c|}
\hline Case Number & : 27-01-001 \\
\hline Hazard & $\begin{array}{l}\text { : Annunciated-detected two aileron control } \\
\text { surfaces float }\end{array}$ \\
\hline Flight Phase & $:$ FLT \\
\hline Effect & $\begin{array}{l}\text { : Possibility of UAV crash because losing the } \\
\text { roll control capability }\end{array}$ \\
\hline Recognition & $\begin{array}{l}\text { : Ground crew recognize from aural and } \\
\text { visual annunciation and aircraft response }\end{array}$ \\
\hline Action & $\begin{array}{l}\text { : If possible, ground crew control aircraft } \\
\text { using pitch and yaw control (UAV flight }\end{array}$ \\
\hline
\end{tabular}
manual)
Criticallity $\quad:$ CAT
Probability $\quad: 10^{-6}$

\section{Fuel System (ATA 28)}

Fuel System or in the world of aviation better known as ATA 28 is a system that has the role of transferring fuel from the tank to the engine so that the fuel can be good energy and produce the desired performance. Here, there are functions of supplying, storing, distributing and even disposing of excess fuel. The Fuel System is one of the most risky systems for UAVs because if this system does not work well, the result is an explosion and the UAV will catch fire. This system has 4 system functions, along with an explanation and analysis of the failure conditions :
a. Accommodate Fuel (28-01)
b. Provide Refueling Capability (28-02)
c. Provide Defueling Capability (28-03)
d. Provide Emergency Fuel Dump (28-04)

Based on the results of the analysis of system level failure conditions on ATA 28 (Fuel System, it is known that there are 8 types of failure conditions. 5 failure conditions are categorized as hazardous, 1 failure condition is categorized as major and 2 failure conditions are categorized as minor. Recognition needed in this system is the existence of aural and visual data that is displayed on the monitor screen and recognizes failure conditions through the difference between the automatic throttle command and the UAV flight parameter data so that the pilot knows that the UAV has experienced a failure / damage to the ATA 28 system. Meanwhile, mitigation can be carried out by the pilot if it is detected and occurs The failure condition is manually controlling the UAV, which can result in an increase in the pilot's workload, but the UAV will still be able to operate and carry out its mission.

Table 8. Failure Condition - ATA 28

\begin{tabular}{|c|c|c|c|c|c|c|}
\hline \multirow{2}{*}{$\begin{array}{c}\text { System } \\
\text { Function }\end{array}$} & \multicolumn{4}{|c|}{ Failure Condition Classification } & \multirow{2}{*}{ Total } \\
\cline { 2 - 6 } & NSE & MIN & MAJ & HAZ & CAT & Case \\
\hline $28-01$ & 0 & 0 & 1 & 3 & 0 & 4 \\
\hline $28-02$ & 0 & 1 & 0 & 0 & 0 & 1 \\
\hline $28-03$ & 0 & 1 & 0 & 0 & 0 & 1 \\
\hline $28-04$ & 0 & 0 & 0 & 2 & 0 & 2 \\
\hline
\end{tabular}

The following is an example of a failure condition that has been analyzed at the ATA 28 system level :

$\begin{array}{ll}\text { Case Number } & : \text { 28-01-001 } \\ \text { Hazard } & : \text { Fuel tank leakage } \\ \text { Flight Phase } & : \text { ALL } \\ \text { Effect } & : \text { Decrease in usable fuel }\end{array}$




$\begin{array}{ll}\text { Recognition } & \text { : Faster than normal decrease in fuel quantity } \\ \text { Action } & \text { : Attempt to isolate leak and revise flight } \\ \text { Criticallity } & : \text { MAJ } \\ \text { Probability } & : 10^{-4}\end{array}$

6. Landing Gear System (ATA 32)

Landing Gear System or in the world of aviation is better known as the ATA 32 system which regulates the entry and exit of the UAV's gear when taking off or landing. The function of this system is designed to move the gear position at the right time. This system has 4 system functions, along with an explanation and analysis of the failure conditions :
a. Provide Roll Control Capability (32-01)
b. Provide Nose Steering (32-02)
c. Provide Air/Ground Status (32-03)
d. Provide Smooth Rolling Capability And Tires Indication (32-04)

Based on the results of the analysis of system level failure conditions at ATA 32 (Landing gear), it is known that there are 13 types of failure conditions. 6 failure conditions were categorized as cathastrophic, 3 failure conditions were categorized as hazardous, 2 failure conditions were categorized as major and 2 failure conditions were categorized as minor. The recognition required in this system is the presence of aural and visual data displayed on the monitor screen and recognizing failure conditions through the difference between automatic throttle commands and UAV flight parameter data so that the pilot knows that the UAV has failed / damaged the ATA 32 system. can be done by the pilot if detected and a failure condition occurs, namely by controlling the UAV manually and controlling the brakes with the remaining surface. This could result in an increase in pilot workload, but the UAV will continue to operate and carry out its mission.

Table 9. Failure Condition-ATA 32

\begin{tabular}{|c|c|c|c|c|c|c|}
\hline \multirow{2}{*}{$\begin{array}{l}\text { System } \\
\text { Function }\end{array}$} & \multicolumn{5}{|c|}{ Failure Condition Classification } & \multirow{2}{*}{$\begin{array}{l}\text { Total } \\
\text { Case }\end{array}$} \\
\hline & NSE & MIN & MAJ & HAZ & CAT & \\
\hline $32-01$ & 0 & 1 & 0 & 0 & 3 & 4 \\
\hline $32-02$ & 0 & 0 & 2 & 0 & 0 & 2 \\
\hline $32-03$ & 0 & 0 & 0 & 1 & 3 & 4 \\
\hline $32-04$ & 0 & 1 & 0 & 2 & 0 & 3 \\
\hline
\end{tabular}

The following is an example of a failure condition that has been analyzed at the ATA 32 system level :
Case Number : 32-01-001
Hazard : Loss of braking capability on both wheel during high energy RTO
Flight Phase : LND
Effect
: Loss aircraft braking capability
Recognition
: No aircraft declaration on brake application on affected wheels
Action
: Use factored landing distance and reduce
Criticallity landing weight limits
Probability
: MIN
$: 10^{-3}$

7. Navigation System (ATA 34)

Navigation System or in the world of aviation better known as ATA 34 has a function in making it easier for pilots to determine the location of the aircraft, flight direction, altitude of the aircraft and can be a guide for the aircraft to be in the correct flight path. This system has 4 system functions, along with an explanation and analysis of the failure conditions :

a. Provide Air Data Reference (34-01)

b. Provide Inertial Reference (34-02)

c. Provide Navigation Data (34-03)

d. Provide Nose And Tail Visual Data (34-04)

Based on the results of the analysis of system level failure conditions at ATA 34 (navigation system), it is known that there are 32 types of failure conditions. And 32 failure conditions were categorized as hazardous. The recognition required in this system is the presence of aural and visual data displayed on the monitor screen and recognizing failure conditions so that the pilot knows that the UAV has failed / damaged in the ATA 34 system. Meanwhile, mitigation that can be done by pilots if detected and a failure condition occurs, namely by controlling the UAV manually and controlling the brakes with the remaining surface. This could result in an increase in pilot workload, but the UAV will continue to operate and carry out its mission.

Table 10. Failure Condition - ATA 34

\begin{tabular}{|c|c|c|c|c|c|c|}
\hline \multirow{2}{*}{$\begin{array}{c}\text { System } \\
\text { Function }\end{array}$} & \multicolumn{4}{|c|}{ Failure Condition Classification } & \multirow{2}{*}{$\begin{array}{l}\text { Total } \\
\text { Case }\end{array}$} \\
\cline { 2 - 6 } & NSE & MIN & MAJ & HAZ & CAT & \\
\hline $34-01$ & 0 & 0 & 0 & 8 & 0 & 8 \\
\hline $34-02$ & 0 & 0 & 0 & 8 & 0 & 8 \\
\hline $34-03$ & 0 & 0 & 0 & 8 & 0 & 8 \\
\hline $34-04$ & 0 & 0 & 0 & 8 & 0 & 8 \\
\hline
\end{tabular}

The following is an example of a failure condition that has been analyzed at the ATA 34 system level :

$\begin{array}{ll}\text { Case Number } & : 34-01-001 \\ \text { Hazard } & : \text { Total loss of air data reference } \\ \text { Flight Phase } & : \text { FLT } \\ \text { Effect } & \text { : Possibility of UAV position on unsafe } \\ & \begin{array}{l}\text { condition (crash or stall), reduce safety } \\ \text { margin, increase crew workload }\end{array} \\ \text { Recognition } & \text { : Air data reference faulty flag active }\end{array}$


Ground crew flight UAV manually using inertial data, and nose and tail visual data

Action : Ground crew flight UAV manually using inertial data, and nose and tail visual data

Criticallity

: HAZ

Probability $\quad: 10^{-5}$

8. Propulsion System (ATA 72)

Propulsion System or in the world of aviation better known as ATA 72 in PTTA MALE provides a mechanical power generator related to the propulsion of the aircraft. This system has 1 system functions, along with an explanation and analysis of the failure conditions : Provide Mechanical Power Generation (72-01).

Based on the results of the analysis of system level failure conditions at ATA 72 (propulsion system) it is known that there are 3 types of failure conditions. 1 failure condition was categorized as cathastrophic, 2 failure conditions were categorized as hazardous. The recognition required in this system is the presence of aural and visual data displayed on the monitor screen so that the pilot knows that the UAV has failed / damaged in the ATA 72 system.Meanwhile, mitigation that can be done by pilots if detected and a failure condition occurs is by turning it off and on. restart the engine. This could result in an increase in pilot workload, but the UAV will continue to operate and carry out its mission.

Table 11. Failure Condition - ATA 72

\begin{tabular}{|c|c|c|c|c|c|c|}
\hline \multirow{2}{*}{$\begin{array}{l}\text { System } \\
\text { Function }\end{array}$} & \multicolumn{5}{|c|}{ Failure Condition Classification } & \multirow{2}{*}{$\begin{array}{l}\text { Total } \\
\text { Case }\end{array}$} \\
\hline & NSE & MIN & MAJ & HAZ & CAT & \\
\hline $72-01$ & 0 & 0 & 0 & 2 & 1 & 3 \\
\hline
\end{tabular}

The following is an example of a failure condition that has been analyzed at the ATA 72 system level :

$\begin{array}{ll}\text { Case Number } & : \text { 72 -01-001 } \\ \text { Hazard } & : \text { Total loss of thrust } \\ \text { Flight Phase } & : \text { ALL } \\ \text { Effect } & \text { : Aircraft will Gliding } \\ \text { Recognition } & : \text { Alert system active } \\ \text { Action } & : \text { Follow AFM for restarting engine } \\ \text { Criticallity } & : \text { HAZ } \\ \text { Probability } & : 10^{-5}\end{array}$

9. UCAV System (ATA 93)

UAV Control Station System or in the world of aviation better known as ATA 93 is a system that regulates aircraft control stations on the ground. In this case, the control station becomes the control center of the aircraft when it is operated, because the pilot who controls the aircraft is at this control station. This system has 2 system functions, along with an explanation and analysis of the failure conditions :

a. Provide Man-To-Machine Interface (93-01)

b. Provide Machine-To-Man Interface (93-02)

Based on the results of the analysis of system level failure conditions on the ATA 93 (UAV Control Station System), it is known that there are 4 types of failure conditions. 2 failure conditions are categorized as major and 2 failure conditions are categorized as minor. The recognition required in this system is the presence of aural and visual data displayed on the monitor screen so that the pilot knows that the UAV is experiencing a failure / damage to the ATA 93 system. Meanwhile, mitigation that can be done is simply to cancel the operational mission.

Table 12. Failure Condition - ATA 93

\begin{tabular}{|c|c|c|c|c|c|c|}
\hline \multirow{2}{*}{$\begin{array}{c}\text { System } \\
\text { Function }\end{array}$} & \multicolumn{4}{|c|}{ Failure Condition Classification } & \multirow{2}{*}{$\begin{array}{c}\text { Total } \\
\text { Case }\end{array}$} \\
\cline { 2 - 6 } & NSE & MIN & MAJ & HAZ & CAT & \\
\hline $93-01$ & 0 & 1 & 1 & 0 & 0 & 2 \\
\hline $93-02$ & 0 & 1 & 1 & 0 & 0 & 2 \\
\hline
\end{tabular}

The following is an example of a failure condition that has been analyzed at the ATA 93 system level :

Case Number : : $93-01-001$

Hazard : Annunciated total loss of weapon firing and

aiming control

Flight Phase : FLT

Effect : Possibility of UAV mission failed

Recognition : Weapon firing and aiming control faulty alert system active

Action : Ground crew abort mission

Criticallity : MIN

Probability $\quad: 10^{-3}$

\section{UAV Control Station System (ATA 99)}

UCAV (unmanned combat aerial vehicles) or in the world of aviation better known as ATA 99 is a system of functions owned by armed drone systems used for reconnaissance, surveillance and attack missions. This system is designed to fulfill the objectives of PTTA MALE with reconnaissance, surveillance and assault missions equipped with surveillance cameras and military weapons inside. This system has 2 system functions, along with an explanation and analysis of the failure conditions :

a. Provide Surveillance Imaging Capability (99-01)

b. Provide Image Post-Processing Capability (99-02)

Based on the analysis of system level failure conditions at ATA 99 (UCAV) it is known that there are 12 types of failure conditions. 8 failure conditions were categorized into catastrophic and 4 failure conditions were categorized as minor. The recognition required in this system is the presence of aural and visual data displayed on the monitor screen so that the pilot 
knows that the UAV is experiencing a failure / damage to the ATA 99 system. Meanwhile, mitigation that can be done is simply to cancel the operational mission and follow flight procedures.

Table 13. Failure Condition - ATA 99

\begin{tabular}{|c|c|c|c|c|c|c|}
\hline \multirow{2}{*}{$\begin{array}{c}\text { System } \\
\text { Function }\end{array}$} & \multicolumn{4}{|c|}{ Failure Condition Classification } & \multirow{2}{*}{$\begin{array}{c}\text { Total } \\
\text { Case }\end{array}$} \\
\cline { 2 - 6 } & NSE & MIN & MAJ & HAZ & CAT & ( \\
\hline $99-01$ & 0 & 2 & 0 & 0 & 4 & 6 \\
\hline $99-02$ & 0 & 2 & 0 & 0 & 4 & 6 \\
\hline
\end{tabular}

The following is an example of a failure condition that has been analyzed at the ATA 99 system level :

$\begin{array}{ll}\text { Case Number } & \text { : } 99 \text {-01-001 } \\ \text { Hazard } & \text { : Total loss of man to machine interface } \\ \text { Flight Phase } & \text { : ALL } \\ \text { Effect } & \text { : Possibility of UAV loss or crash, } \\ & \text { Because total loss of control command } \\ \text { Recognition } & \text { : Control command data faulty flag active } \\ \text { Action } & : \text { No action } \\ \text { Criticallity } & : \text { CAT } \\ \text { Probability } & : 10^{-6}\end{array}$

\section{CONCLUSION \& SUGGESTION}

a. Conclusion

This research produces several outputs, which can be useful for various sectors. analysis of failure conditions carried out on every 10 systems contained in PTTA MALE, resulting in 311 hazards. 26 cases were categorized into minor classification, 65 cases were categorized into major classification, 112 cases were categorized into hazardous classification and 108 cases were categorized into catastrophic classification. Each category has its own probability. The effects and possible actions for each failure condition will vary. however, the recognition for each failure condition was almost the same, namely by utilizing aural and visual data and direct response from the aircraft. The main objective of the results of this analysis is to serve as a guide for pilots in operating PTTA MALE. hopefully these guidelines can help pilots and ground crews in minimizing and avoiding the risk of failure conditions from their operations.

\section{b. Suggestion}

Suggestions for further researchers, it is hoped that the analysis of this failure condition can be continued to the preliminary step or preliminary system safety hazard analysis.

Suggestions for pilots who will use the results of this study as a guideline, if there are still deficiencies in possible failure conditions, then this can be conveyed to the developer, so that recognition can be maximized.

Suggestions for the public, I hope this research can add insight, that actually safety is very important in everything.

\section{REFERENCES}

[1] SAE International (1996), "ARP4761: Guidelines and Methods for Conducting the Safety Assessment Process on Civil Airborne Systems and Equipment", Society of Automotive Engineers, USA.

[2] SAE International (2010), ARP4754A: "Guidelines for Development of Civil Aircraft and Systems", Society of Automotive Engineers, USA.

[3] Raymer, D.P. (2006), “Aircraft Design: A Conceptual Approach", Fourth Edition, AIAA, USA

[4] Fisk, E.R.1997. “Construction Project Administration Fifth Edition”. Prentice Hall. New Jersey

[5] Duffield, C \& Trigunarsyah, B. 1999. "Project ManagementConception to Completion" . Engineering Education Australia. (EEA). Australia.

[6] NATO USAR Specialist Team 2007 . “UAV SYSTEM AIRWORTHINESS REQUIREMENTS (USAR) STANAG 4671". USA 